$\mathrm{C}^{18} \mathrm{H}^{15} \mathrm{~N}^{3}$. In reinem Zustande ist es eine weisse, geruchlose, fast ganz geschmacklose flüchtige Substanz, die bei ungefähr $190^{\circ} \mathrm{C}$. schmilzt und nahe bei $280^{\circ} \mathrm{C}$. zu sieden anfängt, wobei sie jedoch eine partielle Zersetzung erleidet. Sie ist in Alkohol in fast allen Verhältnissen löslich, in kaltem Wasser sehr wenig, in kochendem Wasser leichter löslich und scheidet sich aus letzterem beim langsamen Erkalten in kleinen irisirenden Blättchen ab. Die warme wässerige Lösung zeigt eine schwache aber deutlich alkalische Reaction. Die Basis kann anhaltend mit Kalilauge gekocht werden, ohne die Zersetzung des Cyanäthyls und iuberhaupt ohne eine Veränderung zu erleiden. Wird sie darauf zur Trockne verdampft und im Silbertiegel zum Schmelzen erhitzt, so sublimirt der grösste Theil derselben unverändert auf, ohne dass der Rückstand geschwärzt wird. Die Salze des Cyanäthins haben alle einen bitterlich herben Geschmack und sind in Wasser und Alkohol löslich.

Das Bemühen der Entdecker des Cyanäthins, die Umstände $\mathrm{zu}$ ermitteln, welche die merkwürdige Umsetzung der Elemente des Cyanäthyls zu Cyanäthin bedingen, ist ein vergebliches gewesen. Auch sind alle Versuche, letzteres auf einem anderen, als dem bezeichneten Wege darzustellen, fruchtlos geblieben. (Annalen d. Chem. u. Pharm. B. 65. 269 - 287.)

G.

\title{
Citronensaure Talkerde als Arzneimittel.
}

Das Magnesiacitrat wird, weil es den unangenehmen bittern Geschmack des Magnesiasulfats nicht haben soll, in den letztern Zeiten auch von deutschen Aerzten verschrieben; es giebt aber nur bei grosser Vorsicht, da es stets extemporirt werden muss, klare Auflösungen; man löst die Säure in Wasser und schuittet bis zur ganz nahen Saturation Magnesiacarbonat hinzu, indessen ist es lästig, das Verhältniss beider Substanzen zur Bildung einer vorgeschriebenen Menge des Salzes jedesmal zu berechnen. Der leider für die Pharmacie zu früh verstorbene P y p e r s zu Antwerpen, half dem Uebel dadurch ab, dass er durch Versuche ausmittelte, wie viel eine gewisse Quantität sehr trockner Citronensäure an reiner englischer Magnesia erforderte. - Ein Verhältniss, welches sich von 14 zu 10 herausstellte - und dann ein Gemenge von diesen beiden Substanzen in wohlverstopften Gläsern vorräthig hielt. Versuche hatten ihm ferner gezeigt, dass, um eine Unze 
Magnesiacitrat darzustellen wegen des Krystallwassers etc. nicht 480, sondern 470 Gran des Pulvers genommen werden mussen. Wäre nun z. B. ein Loth Magnesiacitrat zu einer Mixtur verschrieben, so schüttet man 235 Gran des Pulvers in das vorher abgewogene Wasser nach und nach (das jedesmalige Brausen abwartend) hinein. Die Auflösung ist gewöhnlich so klar, dass man sie nicht zu filtriren braucht (Journal de Chim. et de Pharm. d'Anvers.) du Mènil.

Verschiedenheit der durch Gährung aus dem Zucker erzeugten und der in der Fleischflüssigkeit enthaltenen Milchsäure.

H. Engelhardt ist bei Untersuchung einiger Salze der obengenannten Säuren zu Resultaten gelangt, welche die Existenz zweier isomeren Modificationen der Verbindung $\mathrm{C}^{6} \mathrm{H}^{3} \mathrm{O}^{5}$ sehr wahrscheinlich machen oder vielleicht in der ein - und zweibasischen Natur dieser Säure ihre Erklärung finden werden. Die Milchsäuren aus dem Fleisch und dem Zucker zeigten isolirt keine Verschiedenheit, beide lösten sich in Weingeist, Aether uud Wasser sehr leicht und waren nicht krystallisirbar. Sie liessen sich aus dem Zinksalz durch Schwefelwasserstoff abscheiden, und ihre Natronverbindung verhielt sich zu Lösungsmitteln ganz gleich, aber die Kalksalze, die Magnesiasalze, die Zinksalze, die Nickelsalze und die Kupfersalze zeigten aus Wasser krystallisirt verschiedenen Wassergehalt, der von denen aus der Säure des Fleisches viel hartnäckiger zurickgehalten wurde; sie zeigten ferner verschiedene Zersetzungstemperaturen und sehr abweichende Löslichkeitsverhältnisse und äussere Eigenschaften. (Annal. der Chem. u. Pharm. B. 65. 359-367.)

G.

\section{Milchsaures Wismuthoxyd.}

Engelhardt empfiehlt folgende Methode zur Darstellung desselben: Man mischt möglichst mit Wismuthoxyd gesättigte Salpetersäure mit einer concentrirten Lösung von milchsaurem Natron und lässt letateres in nicht allzu grosser Menge vorwalten, weil sonst die Krystallisation verhindert wird. Sind die beiden Lösungen sehr concentrirt, so bildet sich ein Krystallbrei aus Natronsalpeter und dem entstandenen milchsauren Wismuth bestehend. Nlan löst in möglichst wenig Wasser, wodurch keine Trübung verursacht wird (zeigt sich eine solche, so ist sal- 